\title{
Comparative Numerical Aerodynamics Performance Analysis of NACA0015 and NACA4415 Airfoils
}

\author{
Haydar Kepekci \\ Department of Mechatronics Engineering, Nisantasi University, Istanbul, Turkey \\ ${ }^{*}$ Corresponding author E-mail: haydar.kepekci@nisantasi.edu.tr
}

Manuscript received 16 Nov 2021; revised 20 Nov 2021; accepted 1 Jan 2022. Date of publication 10 Jan 2022

\begin{abstract}
The climate crisis caused by global greenhouse gas emissions has led to many disasters around the world in recent years. Some of these disasters are floods in various parts of Europe, melting of Arctic glaciers, and rising water levels in the oceans. People living on islands in Southeast Asian countries are forced to migrate due to rising water levels. With the increase in the frequency of such situations, life on earth is at risk. Greenhouse gas emissions harm not only humans but also animals and plants. The most effective measure that can be taken against this is to stay away from fossil fuels. With the use of fossil fuels, the carbon ratio in the atmosphere increases, and climatic imbalances occur. For this reason, the interest in alternative energy sources is increasing. Wind energy is one of the most widely used renewable energy sources. This is due to the low cost of installation and ease of use. The most important factor affecting the aerodynamic efficiency of wind turbines is the blade profiles. Numerous types of wing profiles have been designed and put into use. In this study, numerical analyzes of NACA 0015 and NACA 4415 airfoils at various angles of attack were performed by determining forces every five degrees between 0 and 20 degrees using ANSYS Fluent commercial software. Lift coefficients and drag coefficients were also calculated for the angles of attack used. According to the analysis results obtained, optimum attack angles were found for each airfoil. As a result, NACA0015 and NACA4415 airfoils were compared in terms of their performance.
\end{abstract}

Keywords: NACA0015, NACA4415, CFD, Pressure Contour.

\section{Introduction}

The winds formed by the irregular arrival of the sun's rays on the earth move from the high-pressure area of the atmosphere to the lowpressure area. In ancient times, the wind was used by sailors for commercial activities. In the following periods, as the need for energy increased, alternative sources began to be sought. Since it is both a clean and safe energy source, electricity has started to be produced from wind turbines [1] [2] [3]. In recent years, wind turbines have become increasingly common. Today, the installed wind power capacity worldwide is $743 \mathrm{GW}$. This prevents the release of 1.1 billion tons of CO2 into the atmosphere annually [4].

Since the turbine part that converts kinetic energy into mechanical energy is the blade profile, it is the most important part of the wind energy system when generating electrical power [5]. Therefore, one of the most popular research topics recently has been airfoils. As a result of the studies, it has been determined that these have the greatest effect on aerodynamics. Airfoil profiles are designed asymmetrically to create aerodynamic force while moving in the air. It is aimed to create a pressure difference between the upper surface and the lower surface of the airfoil [6] [7] [8]. By giving the angle of attack to the airfoils used in wind turbines, the lifting force can be increased, and indirectly the aerodynamic efficiency will be increased [9]. The most commonly used wind turbine blades are NACA profiles. These airfoils are profiles designed by NASA to be aircraft wings. Later on, they have been also used for wind turbines. NACA airfoils also vary greatly in their aerodynamic performance due to profile differences [10] [11].

\section{Literature Review}

In this study, analyzes were made using the ANSYS Fluent commercial software, which is one of the CFD programs. This method, based on numerical analyses using computational fluid dynamic (CFD), has become popular in recent years. Because CFD programs are both economical and give quick results. They provide to inform about aerodynamic and pressure values in detail. CFD analysis may be used at any phase of the process without the need for prototypes. Many studies have been conducted using CFD programs to investigate the effect of NACA airfoils on aerodynamics. Gerontakos and Lee studied the velocity and eddy flow fields around the NACA 0015 airfoil. In their investigations, they focused on the effect of posterior deviation [12] [13] [14]. In their analysis using the NACA 4415 airfoil, Munday and Jacoby found that the airfoil structure had a great influence on the flow separation [15]. Patil et al. investigated the effect of laminar flow on drag and lift forces in a wind turbine blade. They found that as the Reynolds number increased, the lift and drag force increased [16] [17] [18] [19]. Yao et al. investigated the aerodynamic performance of wind turbine blade profiles. They compared the 
results of their studies using the numerical method with the experimental data. As a result, they realized that the turbine blade profile has a great effect on aerodynamic performance [20]. Haque et al. performed some analyzes to understand the effects of Reynolds number and angle of attack in flow analysis. As a result of their study, they found that as the angle of attack increased, the lift force increased [2] [21] [1] [22].

In this study, numerical analyzes have been performed using NACA 0015 and NACA 4415 blades. During these analyses, various angle of attack values has been used. As a result of the analysis, lift, drag, pressure coefficient, pressure, and velocity contour have been calculated. As a result of the calculations obtained optimum values of the angle of attack have been determined for each airfoil separately [21].

\section{Methods}

\subsection{Theoretical and Mathematical Backround}

In the pressure coefficient symbolized by $c_{p}$ can be calculated with the Eq. (1) [23];

$$
c_{p, i}=\frac{p_{i}-p_{\infty}}{\frac{1}{2} p v_{\infty}{ }^{2}}
$$

$P_{\mathrm{i}}$ is the surface static pressure. $c_{\mathrm{p}}$ values at any point on the airfoil surface can be found using first-order Lagrangian interpolation and extrapolation [14] and can be calculated with the Eq. (2);

$$
c_{p}(x)=\frac{\left(x-x_{1}\right)}{\left(x_{p}-x_{1}\right)} c_{p, 0}+\frac{\left(x-x_{01}\right)}{\left(x_{1}-0\right)} c_{p, 1}
$$

It is known that the integration of a pressure distribution on an airfoil chord provides the normal and axial force on an airfoil section when shear stress due to the viscous effect is neglected [24].

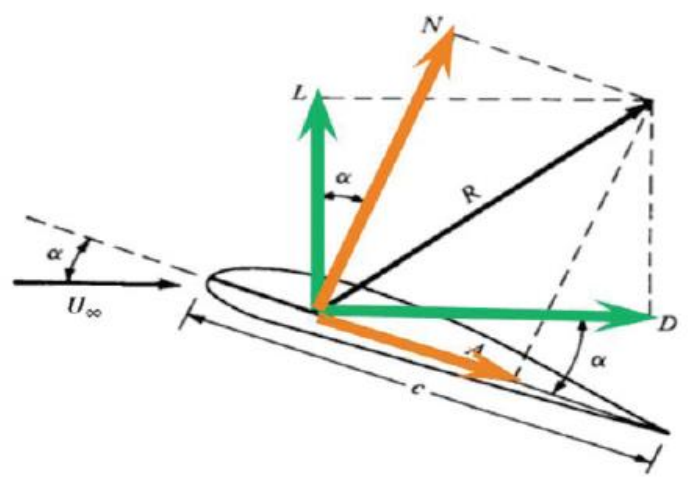

Fig 1. Diagram of aerodynamic forces and their components acting on an airfoil

With $\mathrm{x}$ as the horizontal direction and $\mathrm{y}$ as the perpendicular direction, the normal and axial force equations are Eq. (3) and Eq. (4);

$$
\begin{aligned}
& c_{n}=\frac{1}{e} \int_{0}^{c}\left(c_{p, 1}-c_{p, u}\right) d x \\
& c_{a}=\frac{1}{e} \int_{0}^{c}\left(c_{p, u} \frac{d y_{w}}{d x}-c_{p, 1} \frac{d y_{1}}{d x}\right) d x
\end{aligned}
$$

In the Eq. (5) and Eq. (6), l represents the lower surface and u the upper surface. Pressure coefficients can be calculated for normal and axial force using numerical integration in approximate forms of the above equations. Both surfaces are divided into small panels between each pressure tap position. When $\mathrm{n}$ is a number of panels, the equations can be converted to [25],

$$
\begin{aligned}
& c_{n}=\sum_{i=1}^{n}\left[\left(c_{p M i}-c_{p, i}\right) \Delta\left(\frac{x_{i}}{c}\right)\right] \\
& c_{\alpha}=\sum_{i=1}^{n}\left[\left(c_{p w i} \frac{\Delta y_{w i}}{\Delta x_{i}}-c_{p l i} \frac{\Delta y_{L i}}{\Delta x_{i}}\right) \Delta\left(\frac{x_{i}}{e}\right)\right]
\end{aligned}
$$

To obtain the normal and axial force, the interpolated and extrapolated pressure coefficients will be applied to the Eq. (7) and Eq. (8). The lift and drag coefficient is obtained as:

$$
\begin{aligned}
& c_{\mathbb{D}}=c_{n} \cos \alpha-c_{\alpha} \sin \alpha \\
& c_{d}=c_{n} \sin \alpha+c_{\alpha} \cos \alpha
\end{aligned}
$$

The overall value of the coefficients may be calculated by averaging the same values of the airfoil along the span [12].

\subsection{Aerofoil Confirmation}

The coordinates of the NACA 0015 and NACA 4415 profiles have been taken from the literature. By transferring these coordinates to Pointwise software, two-dimensional geometries have been created and mesh files have been prepared to make them ready for analysis. The generated mesh files are shown in Fig. 2 and Fig. 3. 

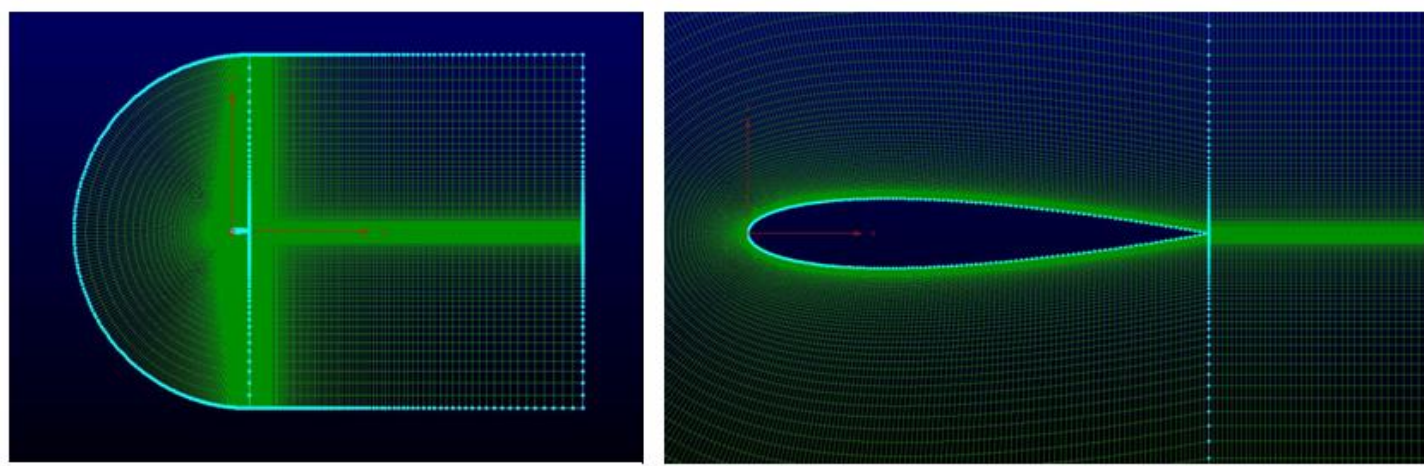

Fig 2. Mesh Generation of NACA 0015
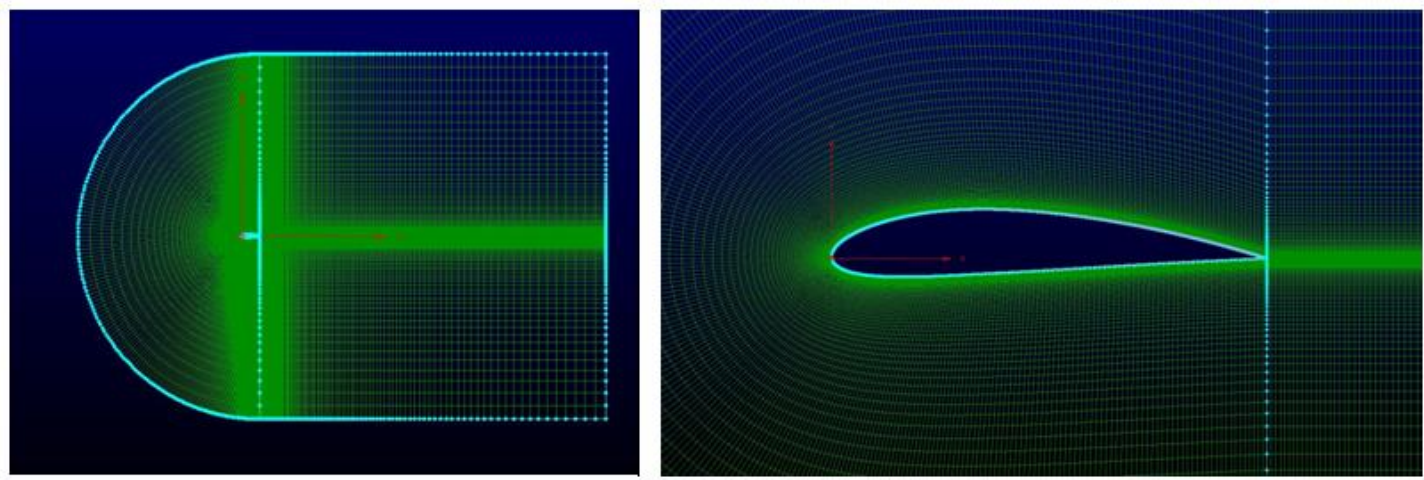

Fig 3. Mesh Generation of NACA 4415

In this is studied, the number of meshes has been increased from 10k to 100k and analyzes have been made. The angle of attack has been accepted as zero in the analysis. At the end of each calculation, the CL/CD value has been calculated. When the variation of this value is negligible, the optimum mesh number is determined. All obtained values are shown in Table 1.

Table 1. Mesh Independency

\begin{tabular}{cccc}
\hline Mesh Number & cL & cD & cL/cD \\
\hline 10,000 & 0.71233 & 0.09900 & 7.195 \\
\hline 20,000 & 0.71812 & 0.08805 & 8.155 \\
\hline 30,000 & 0.73126 & 0.07693 & 9.505 \\
\hline 40,000 & 0.73618 & 0.06623 & 11.114 \\
\hline 50,000 & 0.74216 & 0.06144 & 12.078 \\
\hline 60,000 & 0.74682 & 0.05226 & 14.288 \\
\hline 70,000 & 0.75891 & 0.04994 & 15.195 \\
\hline 80,000 & 0.76211 & 0.04727 & 16.121 \\
\hline 90,000 & 0.76647 & 0.04508 & 17.002 \\
\hline 100,000 & 0.76812 & 0.04500 & 17.068 \\
\hline
\end{tabular}

According to the results obtained using the analyzes made with different mesh numbers, the number of meshes has been determined as 95,000 in the analyzes to be made in the continuation of the study.

Various angles of attack of $5^{\circ}, 7^{\circ}, 9^{\circ}, 11^{\circ}, 13^{\circ}$, and $15^{\circ}$ have been used in the analyzes to examine the flow around the airfoil. When selecting air as the fluid type, velocity of flow is $14.6073[\mathrm{~m} / \mathrm{s}]$, density of fluid is $1.1767\left[\mathrm{~kg} / \mathrm{m}^{3}\right]$, Reynolds number is $10^{6}$, chord length is $1[\mathrm{~m}]$, operating temperature is $298.15[\mathrm{~K}]$, viscosity is $1.009 \times 10^{5}[\mathrm{~kg} / \mathrm{ms}$ ] have been determined. RANS k-e has been chosen as the solution model in the analysis.

\section{Results and Discussion}

\subsection{Contours of Pressure Magnitude}

Figure 4, Fig. 5, Fig. 6, Fig. 7, Fig. 8, and Fig. 9 show the static pressure contours of CFD simulations for NACA 0015 and NACA 4415 airfoils using various angles of attack. It is seen that the upper surface of the airfoils is at low pressure, and the lower surfaces are at high pressure. This is due to the characteristic structure of airfoils. The pressure on the lower surface of each airfoil is greater than the pressure on the upper surface. As a result, the incoming airflow effectively pushes the airfoil upwards, and the coefficient of lift increases. In both airfoils, the static pressure values increased as the angle of attack increased. If we compare the results obtained from the two blades, the static pressure values of the NACA 4415 airfoil are greater than that of the NACA 0015. 


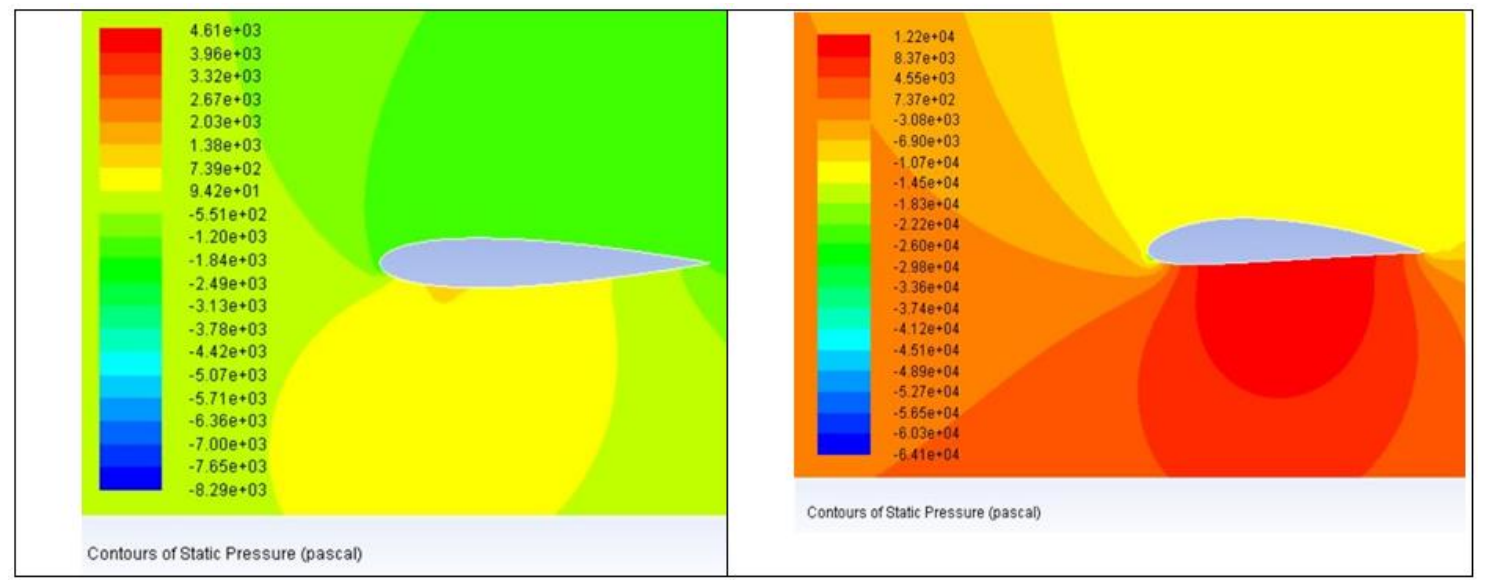

Fig 4. Pressure contours of NACA 0015 and NACA 4415 at $5^{\circ}$ of angle of attack

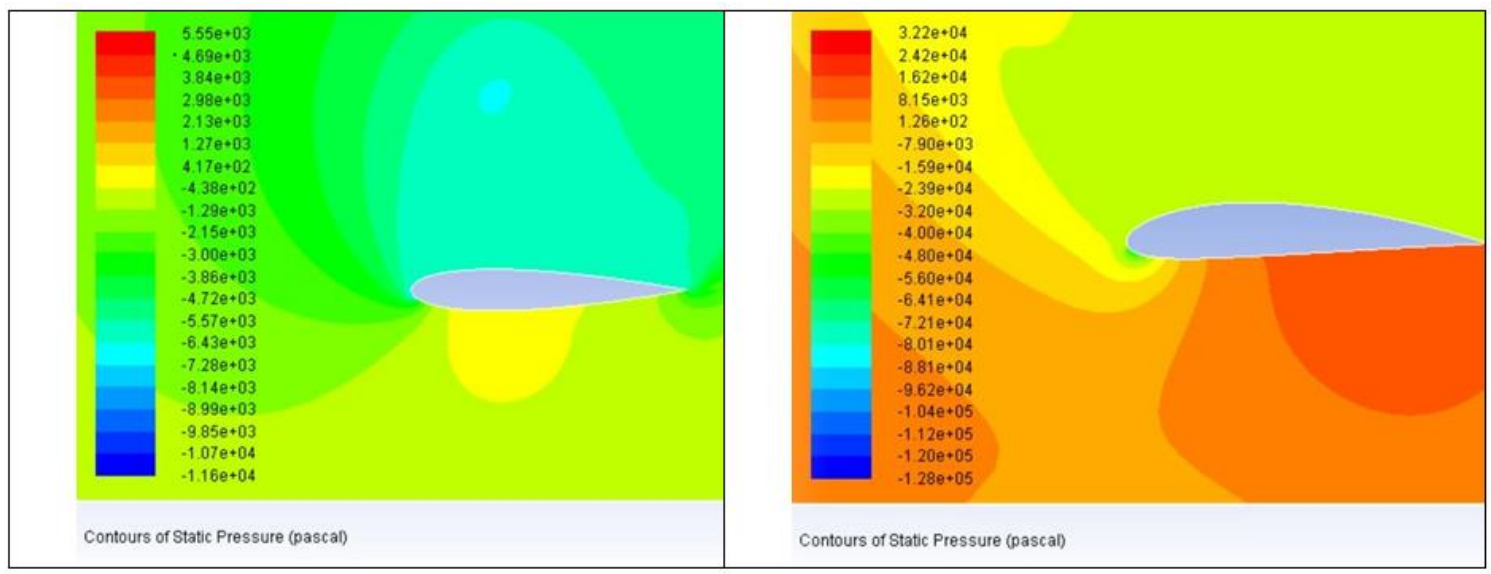

Fig 5. Pressure contours of NACA 0015 and NACA 4415 at $7^{\circ}$ of angle of attack

\begin{tabular}{|c|c|}
\hline $6.07 e+03$ & \\
$5.06 e+03$ & $3.62 e+04$ \\
$4.05 e+03$ & $3.00 e+04$ \\
$3.04 e+03$ & $2.39 e+04$ \\
$2.03 e+03$ & $1.77 e+04$ \\
$1.02 e+03$ & $1.16 e+04$ \\
$7.01 e+00$ & $5.42 e+03$ \\
$-1.00 e+03$ & $-7.37 e+02$ \\
$-2.01 e+03$ & $-6.89 e+03$ \\
$-3.02 e+03$ & $-1.31 e+04$ \\
$-4.03 e+03$ & $-1.92 e+04$ \\
$-5.04 e+03$ & $-254 e+04$ \\
$-6.05 e+03$ & $-3.15 e+04$ \\
$-7.06 e+03$ & $-3.77 e+04$ \\
$-8.07 e+03$ & $-4.38 e+04$ \\
$-9.08 e+03$ & $-5.00 e+04$ \\
$-1.01 e+04$ & $-5.62 e+04$ \\
$-1.11 e+04$ & $-6.23 e+04$ \\
$-1.21 e+04$ & $-6.85 e+04$ \\
$-1.31 e+04$ & $-7.46 e+04$ \\
$-1.41 e+04$ & $-8.08 e+04$ \\
\hline Contours of Static Pressure (pascal) & $-8.69 \mathrm{e}+04$ \\
\hline
\end{tabular}

Fig 6. Pressure contours of NACA 0015 and NACA 4415 at $9^{\circ}$ of angle of attack

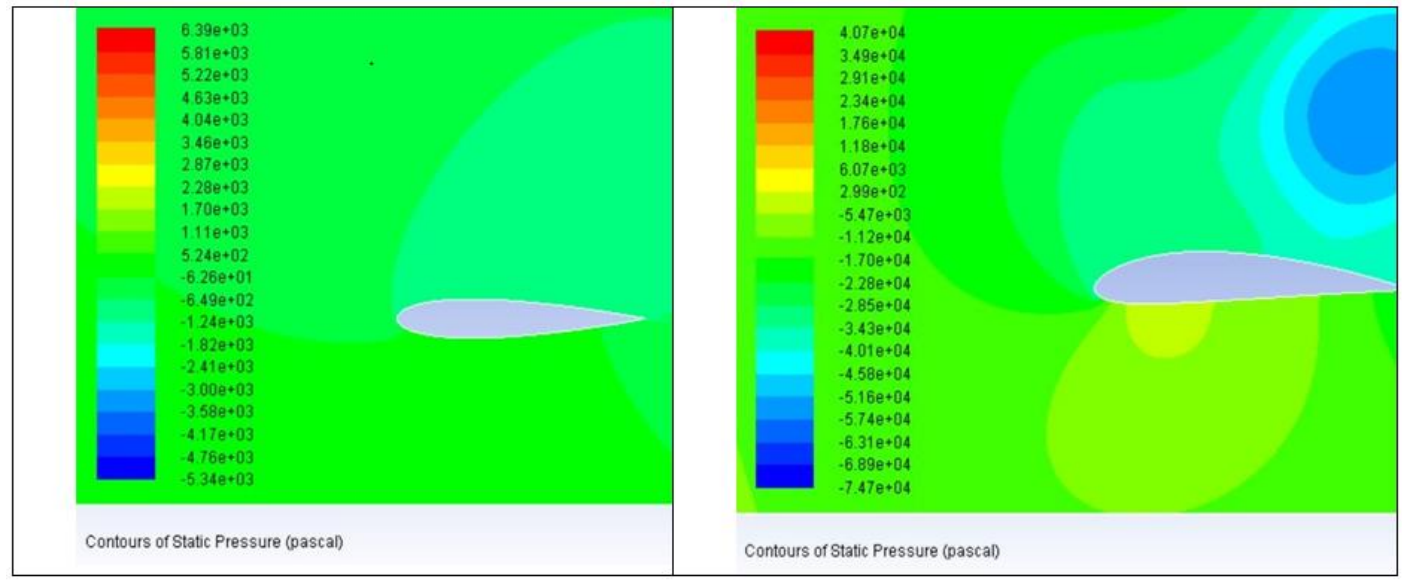

Fig 7. Pressure contours of NACA 0015 and NACA 4415 at $11^{\circ}$ of angle of attack 


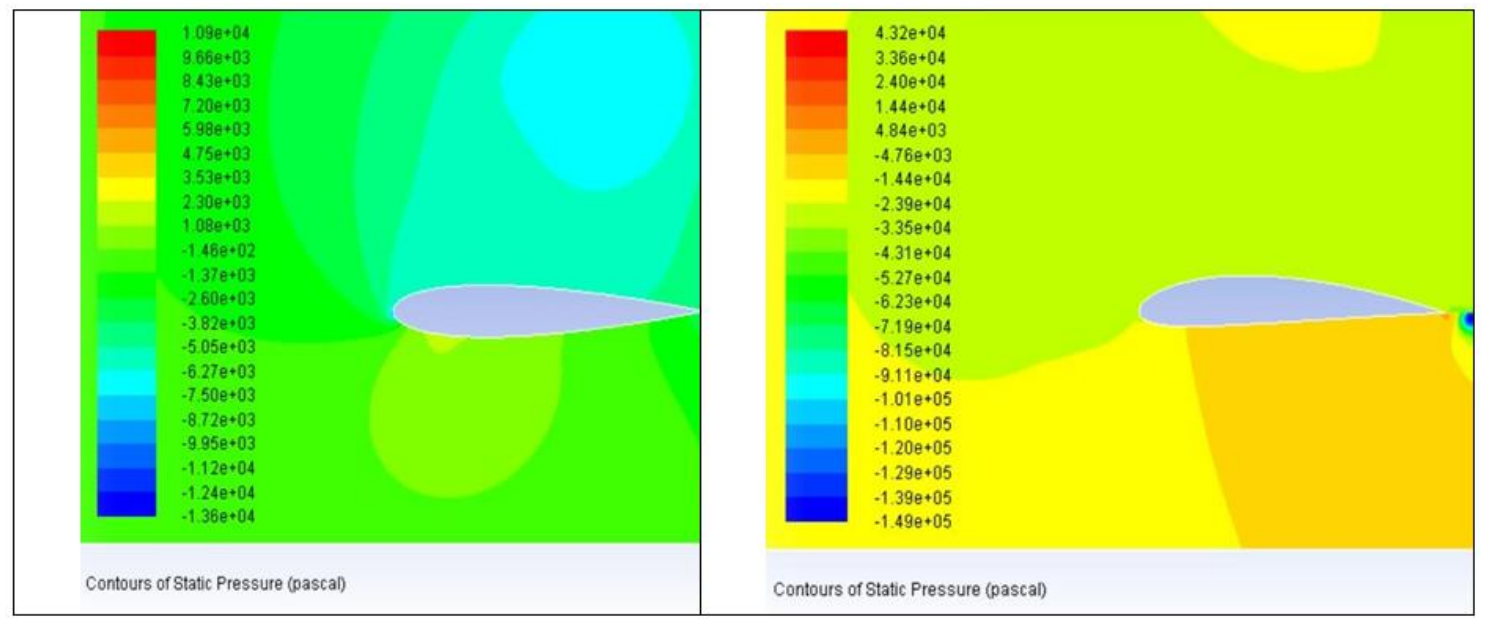

Fig 8. Pressure contours of NACA 0015 and NACA 4415 at $13^{\circ}$ of angle of attack

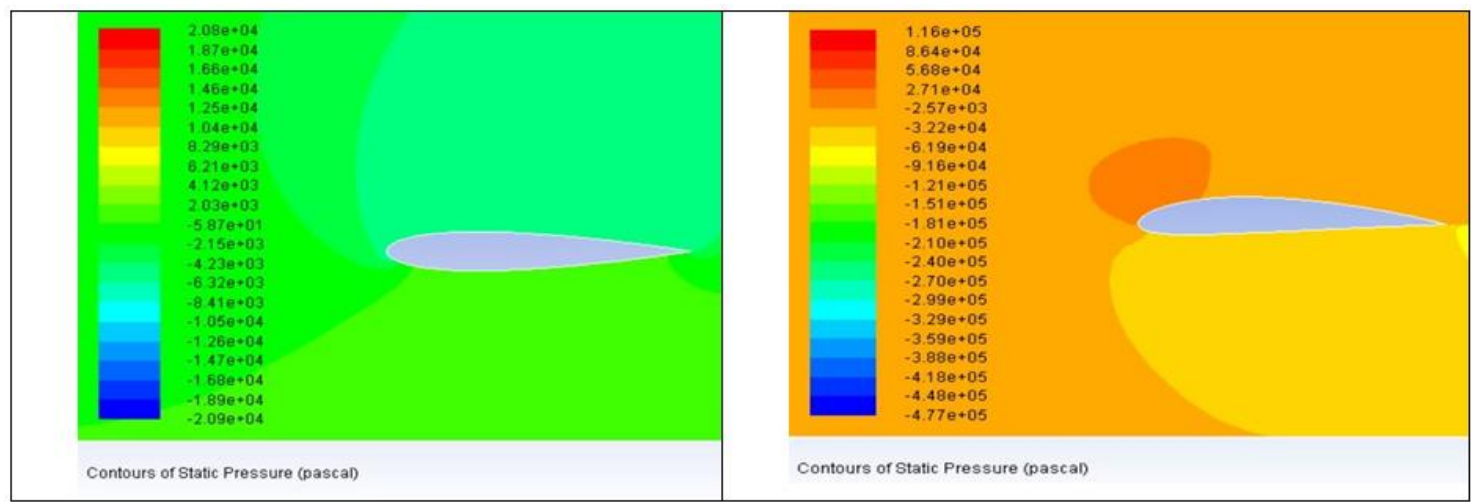

Fig 9. Pressure contours of NACA 0015 and NACA 4415 at $15^{\circ}$ of angle of attack

\subsection{Contours of Velocity Magnitude}

Fig. 10, Fig. 11, Fig. 12, Fig. 13, Fig. 14, and Fig. 15 show the velocity magnitude contours of CFD simulations for NACA 0015 and NACA 4415 airfoils using various angles of attack. At the front end of both airfoil profiles, it is seen that the flow velocity approaches the stagnation point. While the flow velocity increases on the upper surfaces of the airfoils, it decreases on the lower surfaces. If we compare the results obtained from the two blades, the velocity magnitude values of the NACA 4415 airfoil are greater than that of the NACA 0015 . This is because NACA 4415 with an asymmetrical airfoil during flow produced more lifting force than NACA 0015 with a symmetrical airfoil.

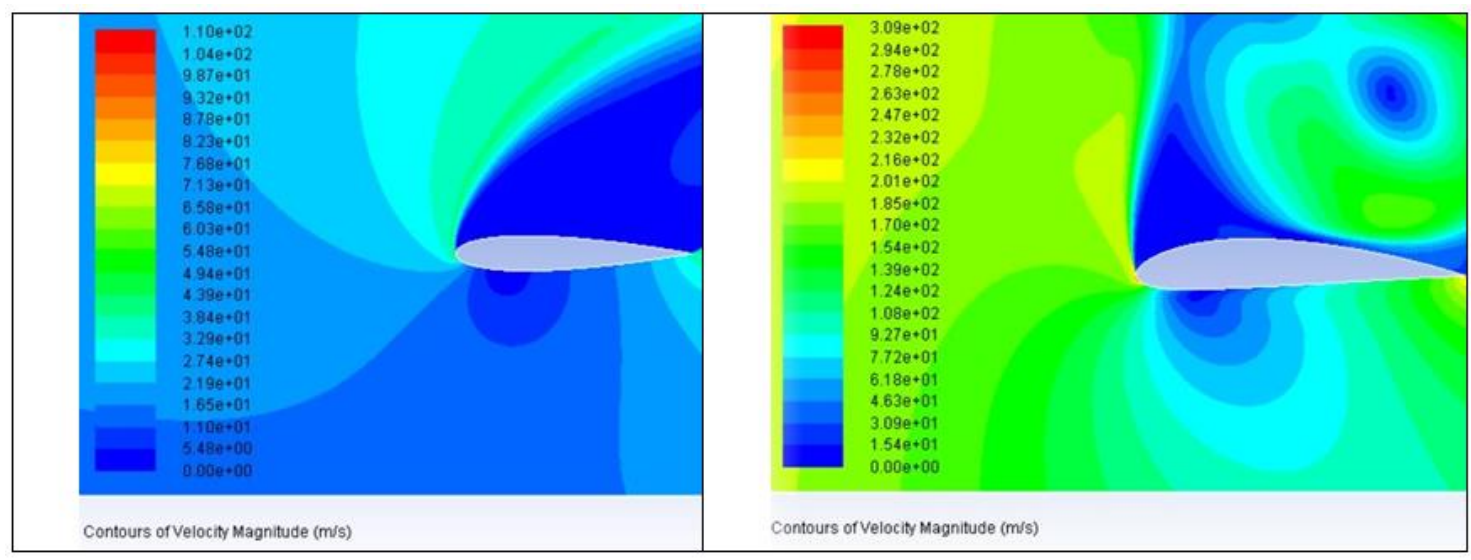

Fig 10. Velocity contours of NACA 0015 and NACA 4415 at $5^{\circ}$ of angle of attack 


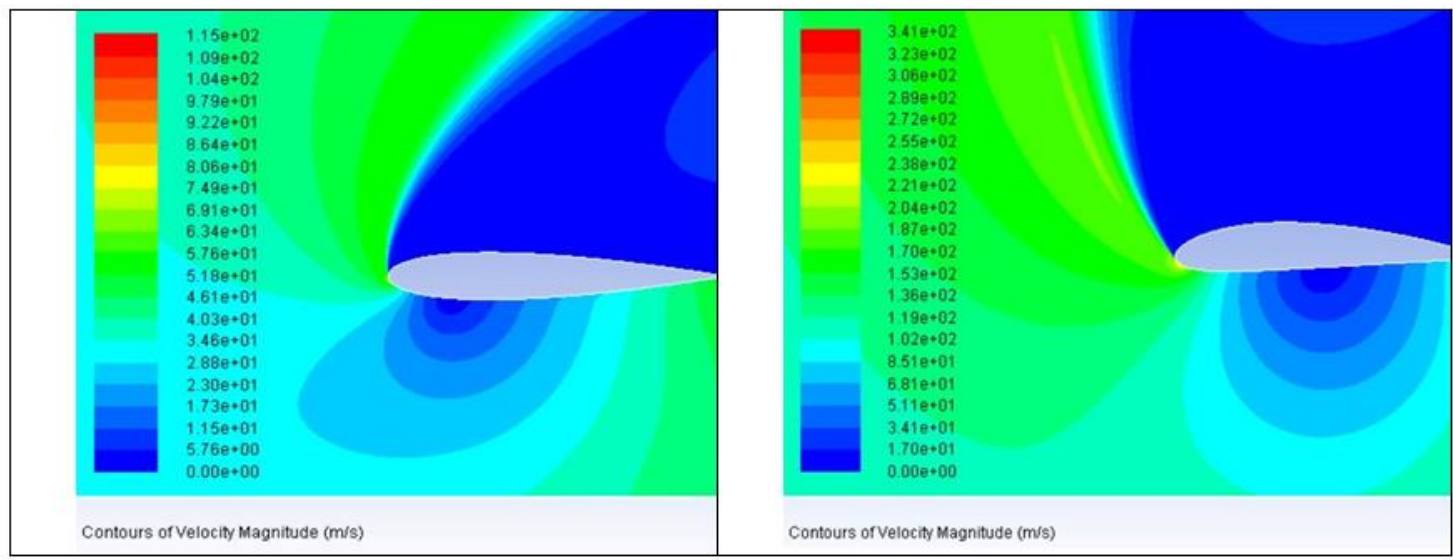

Fig 11. Velocity contours of NACA 0015 and NACA 4415 at $7^{\circ}$ of angle of attack

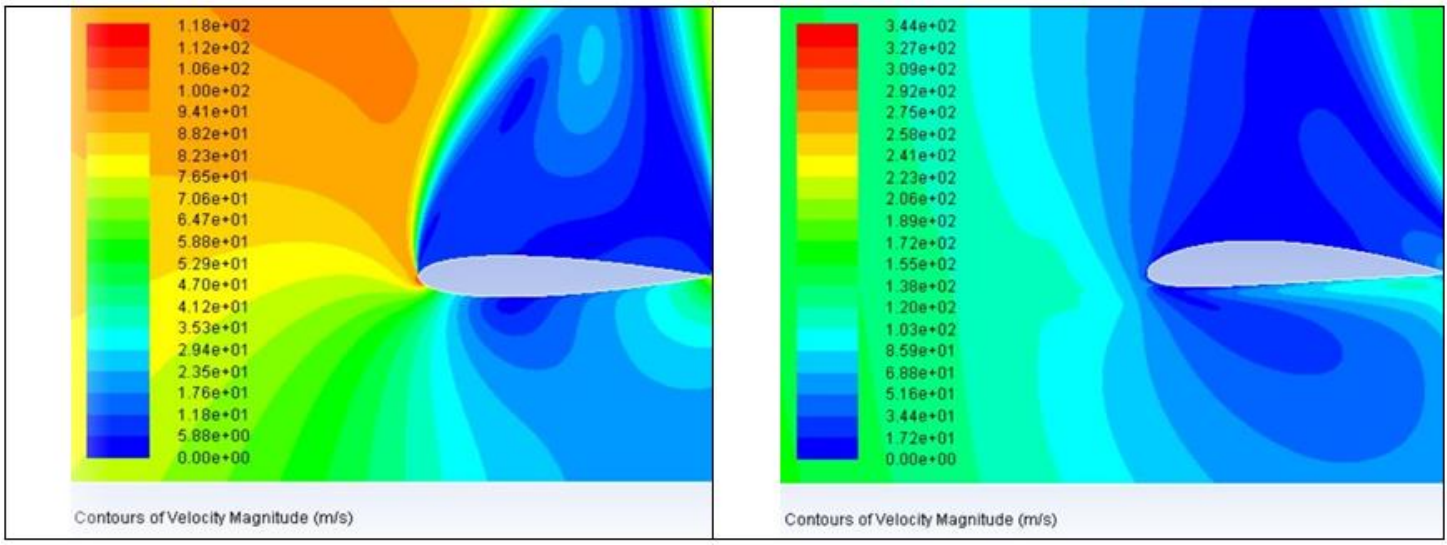

Fig 12. Velocity contours of NACA 0015 and NACA 4415 at $9^{\circ}$ of angle of attack

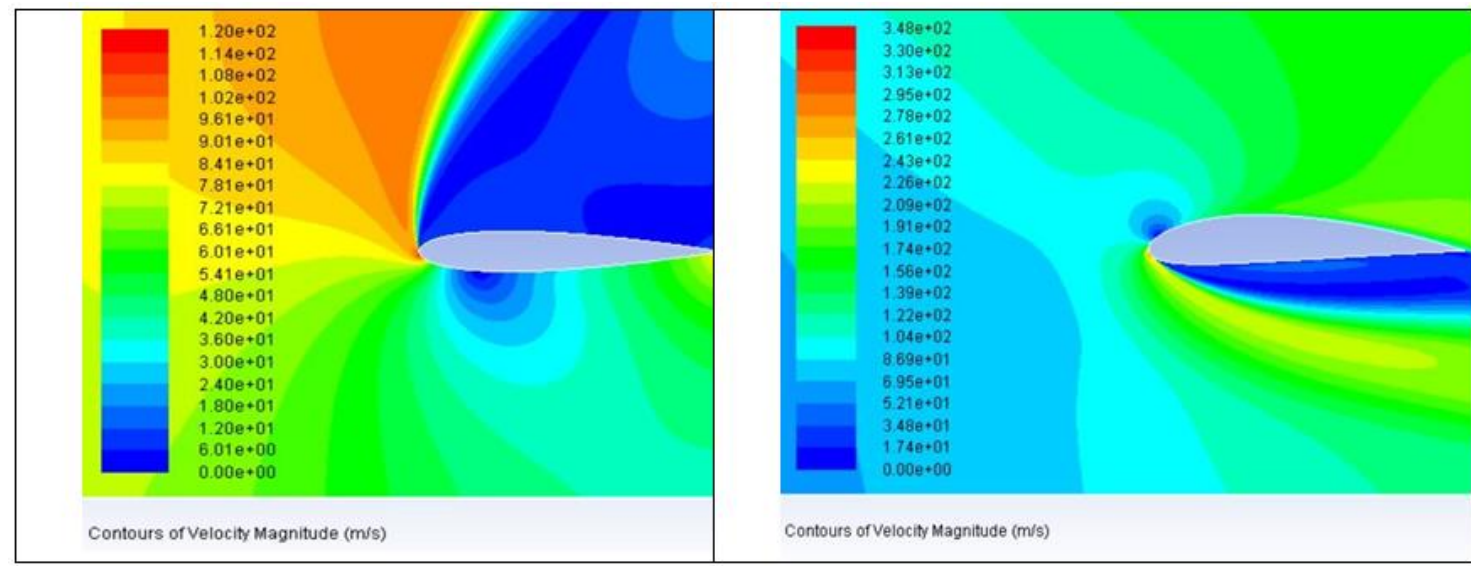

Fig 13. Velocity contours of NACA 0015 and NACA 4415 at $11^{\circ}$ of angle of attack

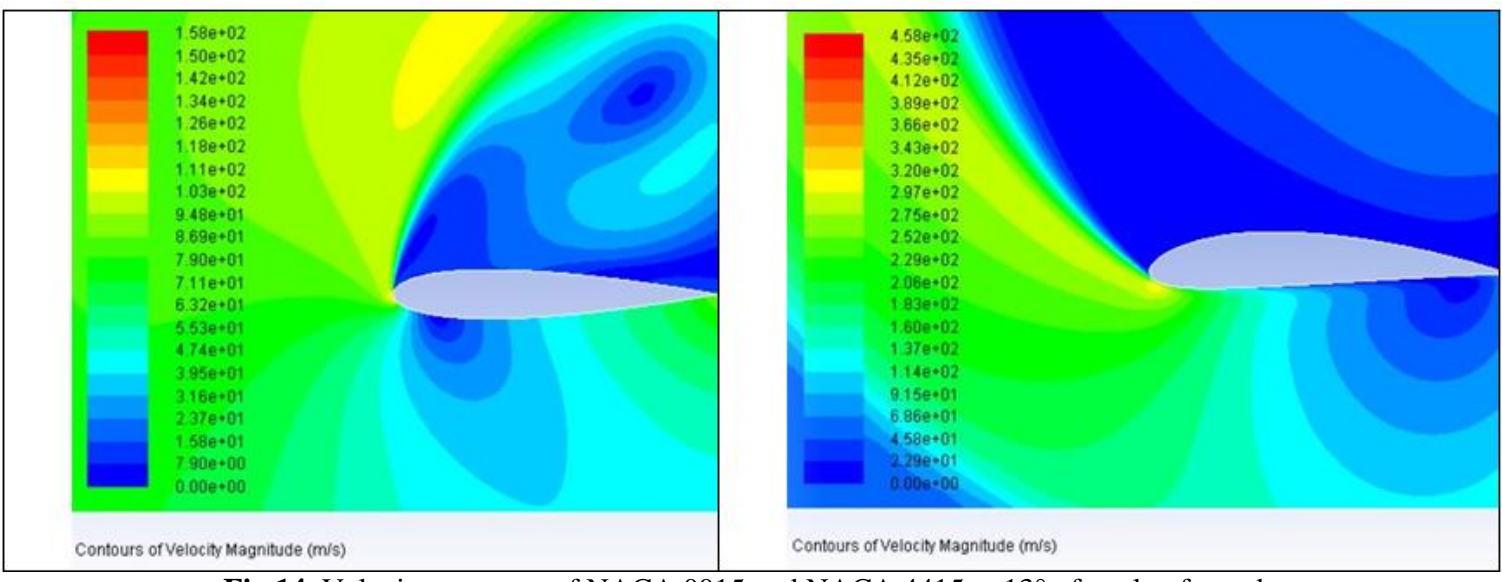

Fig 14. Velocity contours of NACA 0015 and NACA 4415 at $13^{\circ}$ of angle of attack 


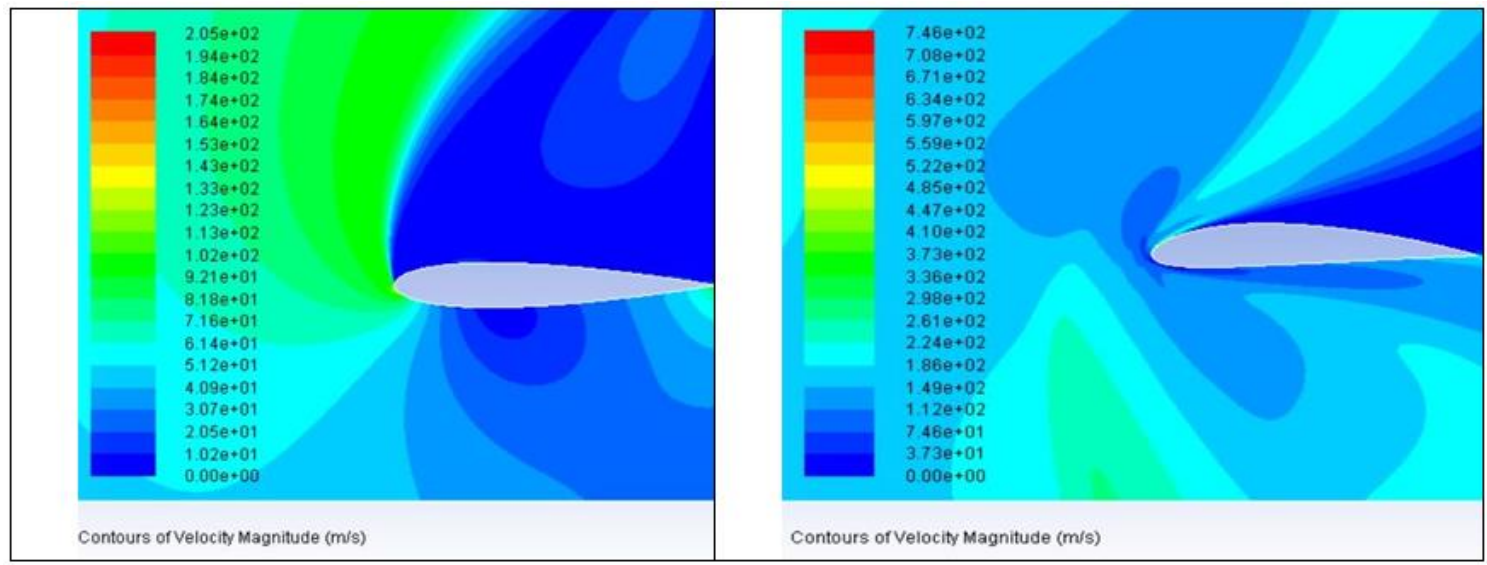

Fig 15. Velocity contours of NACA 0015 and NACA 4415 at $15^{\circ}$ of angle of attack

\subsection{Values of Lift and Drag Coefficient}

The values of lift and drag coefficient are calculated at various angles of attack using the k-w SST turbulence model for NACA 0015 and NACA 4415. Calculated values for NACA 0015 are given in Table 2, and values for NACA 4415 are given in Table 3. Then, cL/cD curves have been created using these values and given in Fig. 16.

Table 2. cL/cD values for various angles of attack for NACA 0015

\begin{tabular}{cccc}
\hline Angle of Attack $\left(^{\circ}\right)$ & $\mathrm{cL}$ & $\mathrm{cD}$ & $\mathrm{cL} / \mathrm{cD}$ \\
\hline 5 & 0.68244 & 0.016705 & 40.8527 \\
\hline 7 & 0.97285 & 0.019684 & 49.4233 \\
\hline 9 & 1.02514 & 0.020412 & 50.2224 \\
\hline 11 & 1.23419 & 0.024621 & 50.1201 \\
\hline 13 & 1.37566 & 0.030276 & 45.4360 \\
\hline 15 & 1.52691 & 0.040247 & 37.9378 \\
\hline
\end{tabular}

Table 3. cL/cD values for various angles of attack for NACA 4415

\begin{tabular}{cccc}
\hline Angle of Attack $\left({ }^{\circ}\right)$ & cL & cD & cL/cD \\
\hline 5 & 1.34537 & 0.02322 & 57.9158 \\
\hline 7 & 1.59858 & 0.02685 & 59.5337 \\
\hline 9 & 1.68812 & 0.02886 & 58.4784 \\
\hline 11 & 1.76941 & 0.03118 & 56.7328 \\
\hline 13 & 1.83647 & 0.03648 & 50.3364 \\
\hline 15 & 1.91424 & 0.04545 & 42.1162 \\
\hline
\end{tabular}

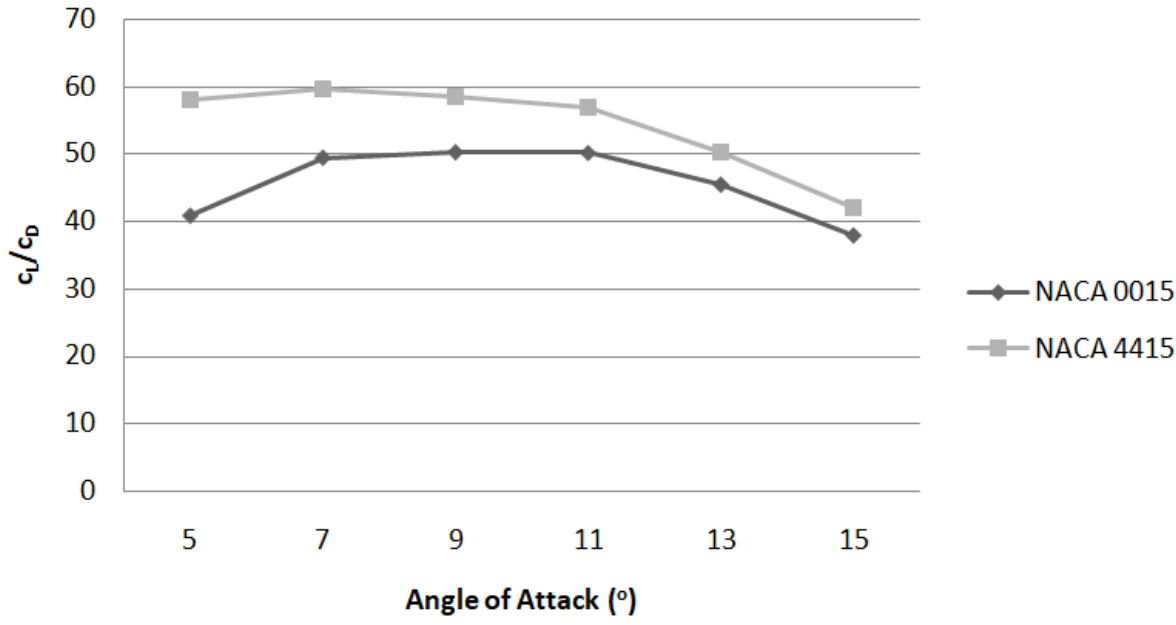

Fig 16. cL/cD curves of NACA 0015 and NACA 4415 for various angles of attack

\section{Conclusion}

Analysis of the aerodynamic performance of the NACA 0015 and NACA 4415 airfoils has been performed a various angles of attack $\left(5^{\circ}\right.$, $7^{\circ}, 9^{\circ}, 11^{\circ}, 13^{\circ}, 15^{\circ}$ ) and using the k-w SST turbulence model, assuming the Reynolds number equal to 106 . From the velocity contours obtained as a result of the analyzes, it is seen that the flow velocity of the upper surface of the airfoil is higher than the flow velocity of the lower surface and that the flow velocity of the upper surface increases with the increase in the angle of attack. From the static pressure contours, it is seen that the static pressure of the lower surface of the airfoil increases with the increase in the angle of attack. 
When the velocity contours of NACA 0015 and NACA 4415 are compared, it is seen that more lift is provided from the bottom surface of NACA 4415. Comparing the static pressure contours of NACA 0015 and NACA 4415, it is seen that NACA 4415 had a greater pressure gradient at each angle of attack. The reason for both cases is thought to be due to the asymmetrical airfoil of NACA 4415. When the $\mathrm{cL} / \mathrm{cD}$ values obtained as a result of the analyzes are examined, it is seen that the $\mathrm{cL}$ and $\mathrm{cD}$ values increase with the increase in the angles of attack. When the $\mathrm{cL} / \mathrm{cD}$ values in Table 2 are examined, it is seen that a $9^{\circ}$ angle of attack is the optimum value for NACA 0015. When the $\mathrm{cL} / \mathrm{cD}$ values in Table 3 are examined, it is seen that a $7^{\circ}$ angle of attack is the optimum value for NACA 4415 .

Considering the static pressure contours, velocity magnitude contours, and lift and drag coefficients for various angles of attack, it is concluded that NACA 4415 with a cambered airfoil is more efficient than NACA 0015 with a symmetrical airfoil at every angle of attack.

\section{References}

[1] K. Reddy et al., "A Brief Research, Study, Design and Analysis on Wind turbine,” J. Mod. Eng. Res., vol. 5, no. October 2015, 2015.

[2] D. Markus, A. Kelder, R. Wüchner, and K.-U. Bletzinger, "Lift Force Reduction by Means of a Diffuser for Gravity Base Foundations in Waves and Currents," Int. J. Offshore Polar Eng., vol. 25, no. 2, 2015, doi: 10.17736/ijope.2015.pf16.

[3] a R. Jenkins, C. S. Van Rooyen, J. J. Smallie, J. a Harrison, M. Diamond, and H. a Smit, "Best practice guidelines for avian monitoring and impact mitigation at proposed wind energy development sites in southern Africa," A Rep. BirdLife South Africa Endanger. Wildl. Trust, vol. 2, 2011.

[4] F. Zahid, A. Tahir, H. U. Khan, and M. A. Naeem, "Wind farms selection using geospatial technologies and energy generation capacity in Gwadar," Energy Reports, vol. 7, 2021, doi: 10.1016/j.egyr.2021.08.165.

[5] T. Ravikumar and S. B. Prakash, "Aerodynamic Analysis of Supercritical Naca Sc ( 2 ) -0714 Airfoil Using Cfd," Int. J. Adv. Technol. Eng. Sci., vol. 02, no. 07, 2014.

[6] C. Cui et al., "Review on an advanced combustion technology: Supercritical hydrothermal combustion," Applied Sciences (Switzerland), vol. 10, no. 5. 2020, doi: 10.3390/app10051645.

[7] Y. Pu, L. Lan, X. Leng, L. K. S. Wong, and L. Liu, "Intracranial atherosclerosis: From anatomy to pathophysiology," International Journal of Stroke, vol. 12, no. 3. 2017, doi: 10.1177/1747493016685716.

[8] A. Cornelissen et al., "Histopathologic and physiologic effect of bifurcation stenting: current status and future prospects," Expert Review of Medical Devices, vol. 17, no. 3. 2020, doi: 10.1080/17434440.2020.1733410.

[9] М. А. Ливеринова and Н. В. Тряскин, "Numerical determination of aerodynamic characteristics of an airfoil in a ground effect," MORSKIE INTELLEKTUAL`NYE Tehnol., no. 1(51), 2021, doi: 10.37220/mit.2021.51.1.024.

[10] J. M. Rainbird, J. Peiró, and J. M. R. Graham, "Blockage-tolerant wind tunnel measurements for a NACA 0012 at high angles of attack," J. Wind Eng. Ind. Aerodyn., vol. 145, 2015, doi: 10.1016/j.jweia.2015.06.006.

[11] S. Jalalul Akbar, M. Maizuar, K. Yusuf, and J. Arfiandi, "Monitoring the Dynamic Behavior of PCI Bridges Using Short Period Seismograph and CSI Bridge Modeling," Int. J. Eng. Sci. Inf. Technol., vol. 1, no. 4, 2021, doi: 10.52088/ijesty.v1i4.168.

[12] J. Gyllenpalm and P. O. Wickman, "The Uses of the Term Hypothesis and the Inquiry Emphasis Conflation in Science Teacher Education," Int. J. Sci. Educ., vol. 33, no. 14, pp. 1993-2015, 2011, doi: 10.1080/09500693.2010.538938.

[13] M. Makky, D. Yanti, and I. Berd, "Development of Aerial Online Intelligent Plant Monitoring System for Oil Palm (Elaeis guineensis Jacq.) Performance to External Stimuli,” Int. J. Adv. Sci. Eng. Inf. Technol., 2018, doi: 10.18517/ijaseit.8.2.2297.

[14] O. C. Zienkiewicz et al., "Numerical Study of Floating Stone (static)," Comput. Geotech., vol. 2, no. 2, 2013.

[15] C. Do Lee, A. R. Folsom, and S. N. Blair, "Physical activity and stroke risk: A meta-analysis," Stroke, 2003, doi: 10.1161/01.STR.0000091843.02517.9D.

[16] K. D. Von Ellenrieder and K. P. Parker, “40th AIAA Aerospace Sciences Meeting and Exhibit Flow Behind Oscillating Foils," Aerospace, 2002.

[17] A. Santhanakrishnan, N. J. Pern, and J. D. Jacob, "Optimization and validation of a variable camber airfoil," in Collection of Technical Papers - AIAA/ASME/ASCE/AHS/ASC Structures, Structural Dynamics and Materials Conference, 2005, vol. 3, doi: 10.2514/6.2005-1956.

[18] D. Munday and J. Jacob, “Active control of separation on a wing with oscillating camber," J. Aircr., vol. 39, no. 1, 2002, doi: 10.2514/2.2915.

[19] M. Mahfut, "Identification and Efforts to Control Infection Odontoglossum ringspot virus (ORSV) on Orchid," Int. J. Eng. Sci. Inf. Technol., vol. 1, no. 1, 2021, doi: 10.52088/ijesty.v1i1.38.

[20] A. H. Brødbæk, K.T. Møller, M Sørensen, S.P.H. Augustesen, "Review of p-y relationships in cohesionless soil," DCE Tech. Rep. No.57, 2009.

[21] B. W. Byrne and M. J. Cassidy, "Investigating the response of offshore foundations in soft clay soils," in Proceedings of the International Conference on Offshore Mechanics and Arctic Engineering - OMAE, 2002, doi: 10.1115/OMAE2002-28057.

[22] Z. Jiang, "Installation of offshore wind turbines: A technical review," Renewable and Sustainable Energy Reviews, vol. 139. 2021, doi: 10.1016/j.rser.2020.110576.

[23] A. Allen and C. Breitsamter, "Transport aircraft wake influenced by a large winglet and winglet flaps," J. Aircr., vol. 45, no. 2, 2008, doi: 10.2514/1.32787.

[24] M. Orr, S. A. Magill, J. A. Schetz, I. F. Marchman, W. H. Mason, and B. Grossman, "Experimental study of the aerodynamic properties of the inboard wing concept," in 39th Aerospace Sciences Meeting and Exhibit, 2001, doi: 10.2514/6.2001-577.

[25] R. R. Meyer and P. F. Covell, "Effects of Winglets on a First-Generation Jet Transport Wing," NASA Ames Reserach Cent., 1986. 